Marine Al Dahdah. From Evidence-based to Market-based mHealth: Itinerary of a Mobile (for)

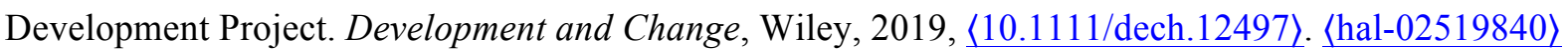

\title{
From evidence-based to market-based mHealth: itinerary of a mobile (for) development project
}

\begin{abstract}
Information and communication technologies (ICT) are increasingly used for development in the Global South and mHealth (health assisted by mobile technologies) plays key role. This paper analyzes the particular relationship to science that characterizes a global maternal mHealth program deployed in Ghana and India. Using Science and Technology Studies (STS), this research relies on qualitative interviews conducted between 2014 and 2016 with funders, implementers and beneficiaries of this mHealth program. This story begins with a randomized controlled trial, a biomedical experiment with a strong positioning regarding science and the production of evidence. But rapidly the scientific stance disappears to give way to the testing and marketing of a product for the digital economy. From science to market, this paper offers to revisit a classical STS topic through the lense of mHealth. It shows how the various experimental forms taken by this project fundamentally diverge from scientific methods and evidence production and at the same time how it nurtures an ongoing instrumental relationship with science. Thus, from clinical research to product marketing, this paper highlights the tenuous link between evidence-based and market-based mHealth in the Global South.
\end{abstract}

\section{Introduction}

Digital technologies are increasingly put at the centre of development policies. ${ }^{1}$ Among these technologies, mHealth (health assisted by mobile technologies) plays a flagship role in this new trend of "digital development." Since 2005, many mHealth projects appeared worldwide, raising many questions about their effectiveness and collateral effects. Mainly directed at health projects in developed countries, research has questioned the effectiveness and relevance of these tools, arguing that digital devices disrupt the administration of care, deregulate the management of confidential health data, and shift health expenses toward solutions that have not demonstrated their effectiveness (Malone 2003; Patrick et al. 2008). International organizations and development agencies took these criticisms and called for

\footnotetext{
${ }^{1}$ In 2015, the United Nations body for development and international trade (UNCTAD) published a first report on "digital development," which asked to put information and communication technologies (ICTs) at the core of the post-2015 development agenda (UNCTAD Digital development Report: http://unctad.org/meetings/en/SessionalDocuments/ecn162015d2_en.pdf). The same year, the "Principles for Digital Development" were launched by an international consortium with WHO, UNDP, the World Bank, and the Bill \& Melinda Gates Foundation at its forefront to reaffirm the central role of ICT for development policies. In 2016, the World Bank annual development report called "Digital Dividends" was completely ICT-centered (Digital dividends, World Bank's 2016 world development report: http://www.worldbank.org/en/publication/wdr2016)
} 
experimental studies on mHealth to prove the effectiveness of these devices (World Bank 2011). The "Motech" project, studied in this paper, was created precisely to meet this evidence requirement. Using Science and Technology Studies (STS) as a dominant theoretical framework, this paper questions mHealth experimentation in the Global South and its connection with Science and business.

Several STS scholars have already examined the particular relation to knowledge and power at stake in the recent experiments carried out within the framework of global health programs in the Global South. Petryna develops the concept of "experimentality" in her work on the mass globalization of clinical trials, a term that merges the notion of experimentation with that of governmentality (Foucault 1994). Experimentation becomes a mode of government and a way of revealing other stakes of power behind the production of medical knowledge. Petryna shows that the decentralization of clinical trials from rich countries to emerging countries by displacing the biomedical object in another context exposes the disengagement of states, the lack of regulation and transparency of these forms of experimentation, and proposes a mercantile vision of biomedical research (Petryna 2009). Richard Rottenburg fits in with this analysis of experimentality in the Global South and declares that the experimental programs place the developing world in a position of dependence on the developped one (Rottenburg 2009a). The scientific motivations of this experimentality are associated with personal ambitions, the need to find "virgin" biomedical subjects, the possibility of collecting sensitive data in looser legal contexts, and the need to reduce the costs of biomedical research. Vinh-Kim Nguyen extends the notion through the concept of "government of experimentation" to show that the humanitarian cause justifies a state of exception where any form of "experimentation" is legitimized by a sense of emergency (Nguyen 2009). These authors show that experimenting in the Global South thus presents multiple interests for the Global North. This article aims to show how new mHealth projects fit into this pattern and create a very particular link between Science and business through the imperatives of a growing mobile economy in the Global South.

Based on qualitative interviews conducted between 2014 and 2016, with funders, implementers and beneficiaries of mHealth programs in Ghana and India, ${ }^{2}$ this paper tells the story of the Motech project in three parts. The first part focuses on the genealogy of this mHealth program, its implementers, aims and implications. The second part deals with the methodology of the program and its forms related to the production of knowledge and a "scientific" stance on mHealth. Those experimental phases of the project relate to the wider field of biomedical experiments in a postcolonial context and evidence-based practices of development and Global Health programs. Finally, the third part of the article discusses the link between scientific and market-based evidence by analyzing the commercialization of Motech and its export from Ghana to India. From science to market, this paper revisits an

\footnotetext{
${ }^{2}$ One hundred indepth interviews were conducted with professionals involved in mHealth: Ministries, Public Health Agencies, United Nations agencies, NGOs, mobile entrepreneurs, digital agencies, mobile phone operators, and private foundations. Among these interviews, forty concerned stakeholders directly involved in the implementation of Motech. Motech fieldwork was conducted in 2014 and 2015 , in two districts of Central Ghana and two districts of Bihar in India, among 200 women, 50 community health workers and 35 implementers, all involved in the Motech project.
} 
enduring STS concern through the lens of mHealth. It shows how the various experimental forms taken by Motech fundamentally diverge from science from both methodological and knowledge production standpoints, and how at the same time it establishes an ongoing instrumental relationship with science. Thus, from clinical research to product marketing, this paper highlights the tenuous link between evidence-based and market-based mHealth in the Global South.

\section{The genealogy of Motech}

The Mobile Technology for Community Health project (Motech) was designed to improve maternal and child health in developing countries by supporting, through mobile phone messages, pregnant women and lactating mothers in rural areas. It was launched in Ghana in 2010 as a free mobile device, which combines SMS alerts and vocal messages for women and community health workers. In 2013, the project was exported to the State of Bihar (India) as a fee-based service (women had to pay 1 rupee per message) and extended to the rest of India in 2016. Motech began in Ghana with a randomized controlled trial, a biomedical experiment with a strong positioning regarding science and the production of evidence. But rapidly the scientific stance gave way to the testing and marketing of a product for the digital economy.

\section{Proving the efficacy of mHealth}

The Bill \& Melinda Gates Foundation (BMGF) is Motech's main sponsor from the Ghanaian launch in 2010 until the Indian national extension in 2016. Each year, BMGF allocates more than $\$ 3$ billion in grants to development projects, one-third of which is dedicated to "Global Health" programs. For BMGF, improving health essentially requires new technologies (Fejerskov 2017). By suggesting the use of mobile technologies to improve maternal health in the developing world, Motech fits perfectly into a "Gatesian" vision of health: a precise technological response to a particular health issue. The proposed mHealth technology is even more innovative than a vaccine or a drug program, as no mHealth devices had ever been deployed in the Global South before 2008.

From the start, Motech was presented by its creators as an exemplary initiative to replicate around the world: "It is intended that Motech will be launched nationally in Ghana, and that this will become a showcase for replications throughout Africa and the world" (Grameen Foundation 2011). This project, which began in Northern Ghana, presented a particular history, characteristics, and promises. Motech Ghana comprised two interconnected applications, "Mobile Midwife," which sent health vocal messages to pregnant women and young mothers, and "Nurse's Application," which allowed community health workers to collect health data on these women via mobile devices. The Ghanaian project initiated in 2010 was the first phase of Motech. It relied on a partnership between the BMGF, the Columbia University Mailman School of Public Health and the Ghanaian Ministry in charge of health infrastructures (GHS). The last two institutions have been working together since the early 2000s on the national implementation of a community-based primary health service called the Community-based Health Planning and Service Initiative (CHPS). At that time, 
they were also committed to the Ghana Essential Health Intervention Programme (GEHIP), launched in 2009 to improve the functioning of CHPS.

The goal of these two initiatives was to transform the way primary care is provided in Ghana: health workers were not waiting for patients to come to the health center anymore, they met them in communities and provided basic care in the villages (Ntsua et al. 2012; John K. Awoonor-Williams et al. 2013). This community health system was first tested and implemented in the Upper-East region of Ghana where the GHS has a research center, the Navrongo Health Research Center, which has been working on monitoring primary health care in Ghana since the 1990s. The Navrongo Health Research Center enabled the GHS to deploy clinical trials and health programs in Ghana. In 2010, in the middle of the GEHIP program aimed at improving the Ghanaian community health program, a clinical trial on mHealth was initiatied: the Motech Randomized Control Trial.

\section{$R C T$, a new gold standard?}

Motech was born in the midst of a new trend of evaluation in the field of development and health, broadly called "experimental studies" and contributed to it in an interesting way. Indeed, the last decade saw the emergence of a new field of development evaluation: Randomized Control Trial (RCT) experimental methods. The medical RCT methods have been adapted to the development issues and contexts of poor countries. They were very successful in the mid-2000s and were presented as "rigorous" and "scientific" by their promoters (Banerjee, Duflo, and Maistre 2012). Development economists in favor of the experimental method chose to apply this method to social issues or economic problems by testing several tools to address specific issues on a micro-scale. In order to measure its impact, the experimental method aims to compare the situation resulting from a project with that which would have occurred if it had not been put in place. The difficulty of this method is to construct the reference situation "without a project" (referred to as a counterfactual or as a control site in relation to the intervention site), because this is by definition never observed. The solution proposed by the experimental method consists of randomly selecting two samples from the same population that could benefit from the project, implementing it within only one of the groups, and investigating both before and after the project. The statistical properties derived from the theory of surveys ensure that on average the differences observed between beneficiaries and non-beneficiaries can be attributed to the project.

Established in 2003 by economists Abhijit Banerjee and Esther Duflo, the Jameel Lateef Poverty Action Lab (J-PAL) has been one of the most influential promoters of RCTs on development issues. Ten years after its creation, J-PAL launched over 400 evaluations, mainly in Africa and India, focusing on three central themes: microfinance, health, and education. Banerjee and Duflo explicitly reject the ideological nature of development policies and wish to replace them with measures that are both neutral and objective, since they are "scientifically" tested by the RCTs at a more "micro" level, and therefore more concrete, and are supposed to be free of any partisan consideration thanks to statistical comparison (Banerjee, Duflo, and Maistre 2012). This approach has met with exceptional success and is increasingly dominant in the field of development economics. Some economists show that it 
exerts a crowding-out effect on other approaches, taking the examples of studies commissioned by the World Bank: "In the period 2000-2004, barely 20\% of the evaluations were RCTs. In the following five years, the proportions were reversed completely ( $76 \%$ were RCTs). The number of RCTs is constantly increasing, the evaluations applying other methods stagnate or even regress" (Bédécarrats, Guérin, and Roubaud 2013, 4).

Motech was born in the midst of this new evaluation trend, but it did not try to test a drug or a vaccine. It attempted to evaluate a new digital technology of care. This digital foundation had an impact on its trajectory. Funded by BMGF, the trial was carried by the Ghanaian Ministry of Health (GHS) and a research team from Columbia University. Because GHS and Columbia did not master the "technological" dimension of the project, a technical partner in charge of developing the digital platform was necessary. On the recommendation of BMGF, the Grameen Foundation joined the research project as a technical partner. BMGF had financed Grameen Foundation ICT for development projects since 2006. ${ }^{3}$ Motech was built on the model of RCT, trying to understand if the mobile phone can improve community health from the comparison between one sample of individuals that used the mobile phone to collect health data and send information to pregnant women and another sample that did not use this technology. The randomized trial of Motech, however, proved to be very difficult to implement. ${ }^{4}$

The role of Columbia University was central to this experiment, reflecting the frequent involvement of academics in mHealth projects in the Global South. Indeed, academics can be involved at different levels. For example, through the Public Health, Informatics or Engineering Departments of universities, they can conduct critical research on mHealth devices, propose models of analysis, reference the literature on these issues, conduct an evaluation of pilot projects, or clinical trials, remaining outside implementation of the project handled by a third party. Or, through structures within or on the fringes of the university, they may be involved in, or even at the origin of, the formalization and implementation of mHealth projects. Most often, these researchers depend on U.S.-based universities (Columbia, MIT, Berkeley, or Johns Hopkins) or emerging country-based universities (University of Pretoria, Manila, or Makerere). ${ }^{5}$ It is sometimes difficult to distinguish between researchers working "on" mHealth (conducting external evaluation on mHealth devices) or "for" mHealth (engaged as consultants in private institutions outside the universities to implement mHealth devices). Their scientific outputs are published in peerreviewed journals regardless of their level and nature of commitment. In this regard, Columbia's role in the Motech project was unclear. The Motech device was partly designed by Columbia University and GHS amidst a broader community health program they have been implementing together for years. The university was therefore both judge and party in this mHealth project. At the launch of Motech, Columbia researchers co-authored several papers on the principle and deployment of Motech (MacLeod et al. 2012; Awoonor-Williams

\footnotetext{
Interview with A., Grameen Foundation, Accra, 06/14

${ }^{4}$ Interview with E., Former GHS, Accra, 06/14

5 (GSMA 2014)
} 
et al. 2013). However, only a few months after the launch of the trial during summer 2010, Columbia — the RCT scientific guarantor — would withdraw from it.

\section{2. "Science" as a mode of intervention}

The Motech project was conceived and developed as a randomized controlled trial (RCT) with an intervention site where the mHealth device was deployed and a control site to understand the impact of the device on the tested population. This particular form of scientific study used in medicine for clinical trials has been spreading for some years in public health, evaluation of development programs, and social sciences, under the influence of development economists (Banerjee, Duflo, and Maistre 2012). The RCT principle is neither a methodological innovation nor a revolutionary scientific advance at the beginning of this millennium. It has been used in medical research for more than 50 years to test the efficacy of several therapeutic approaches or molecules in a patient population (Marks 2000). Its use outside developed countries is, however, more recent and the anthropologist Adriana Petryna has shown that pharmaceutical laboratories, in their search for "naïve" (or less medicated) subjects and sites with less constraining ethical norms and reduced costs, have gradually turned towards "less rich" countries-Brazil and Poland in this study - to test their new molecules (Petryna 2009). Beyond pharmaceutical experiments, the extension of randomization to the field of public health interventions is also a relatively recent phenomenon. According to Vincanne Adams, the requirement for numerical proof displayed by the RCTs constitutes a rarely questioned pillar of the international health programs of the new millennium. These programs must demonstrate their usefulness and scientifically prove that they are beneficial. Adams then describes the use of randomized controlled trials in these programs as a "gold standard" to prove their efficacy, a systematic method that gives "an illusory sense that there is a firmness and stability in the intrinsically messy social world of people, health and disease" (Adams, 2013, 87).

\section{The impossible RCT ?}

In response to the massive success of RCTs, some development economists questioned the scientific validity of the method, putting into perspective its advantages and disadvantages compared to other quantitative methods. In particular, they have shown that the method only applies to a very circumscribed field, and this type of experimental study has many limitations, including biases that may limit the reliability of the results obtained (internal validity threats); limited capacity to explain situations other than the particular case studied (threats to external validity); the difficulties of generalizing its use (Bédécarrats, Guérin, and Roubaud 2017). Others question the ideal of political and scientific neutrality on which this methodology is based, and demonstrate that RCTs on development issues serve primarily to provide donors with an exhaustive list of good and bad development policies and to rank them (Jatteau 2014). They also demonstrate precisely how results may be shaped, both during and after their production, by socio-political forces (Faulkner 2014). Indeed, the 
epistemological problems and methodological difficulties inherent in these experiments can be verified by Motech's story.

Only few months after the launch of the Motech project, Columbia University pulled out from Motech RCT. The actors involved in Motech remain very evasive about this. First, they mention difficulties in implementing the randomized controlled trial when the technology itself was being tested: "The first evaluation didn't end successfully. It was based on randomized control trials RCTs. The problem was that you cannot start evaluation of products when the project is being in pilot testing. " For the professionals who participated in this first phase of Motech, the confusion or overlap between the implementation of the project and its evaluation carried out by the same actors over the same period of time regularly recurred as a logistical and ethical issue. But, they also evoke "political" reasons that would explain Columbia's withdrawal from Motech trial: "For a whole host of political reasons, the Columbia thing didn't fully work out."7 After several interviews and "off the record" discussions, one could finally understand the "political" reasons for this opting out. Several actors spoke of tensions and even open conflicts between Columbia and the Grameen Foundation on paternity, control, and ownership of Motech, as well as problems of leadership and guidance in the evaluation of the device: "There was a power play, this they hardly talk about. Columbia University and Grameen Foundation had their own views. Grameen is an institution who wants to remain in business all the time, Columbia University came as a research academy, they were interested in the research component of the project insuring that evidence generated is rigorous and well documented. [...] Columbia didn't finalize the evaluation component, because they think conditions were not appropriate to conduct the $R C T$ and generate evidence [...] There were so many biases, so many manipulations, interferences. " 8 According to former employees of the project, the data collected on site by Motech teams were biased to favor a positive evaluation of the device, which would have caused serious tensions between the Grameen Foundation in charge of deploying the Motech intervention and Columbia trying to protect the scientific conditions of the RCT. Based on these pre-existing tensions, a controversy tarnished the prestige of the Columbia team in charge of the trial and ended the involvment of the university in Motech.

In spring 2010, the communication manager of Motech, Yaa Busumtwi, accused the principal investigator from the Columbia research team, James Philips, of fraud, unethical conduct in connection with the research, and unfair dismissal, in a video press release and then at a press conference on May 15, 2010. ${ }^{9}$ One of the main accusations was the attempt to conceal the dominant role of the three American institutions (Grameen, Gates and Columbia) in the development of Motech and the purported ownership of Motech by the GHS, whereas the latter did not actually have any rights on the Motech platform. ${ }^{10}$ E-mails sent by James

\footnotetext{
${ }^{6}$ Interview with E., Former GHS, Accra, 06/14.

${ }^{7}$ Interview with A., Grameen, Accra, 06/14.

${ }^{8}$ Interview with B., Former GHS, Accra, 06/14

9 Yaa Bosumtwi. "Yaa Bosumtwi vs. James Phillips: Fraud, Blackmail \& Illegal Labor Practices at Columbia University on Vimeo." Vimeo, May 2010. http://vimeo.com/12607266. "Yaa Bosumtwi Fights and Stands Firm against Columbia University’s Threats | Diasporian News 2010-05-09." Consulted on 16th of April 2016.

${ }^{10}$ The two central protagonists-Philips and Bosumtwi-did not respond to our requests for interviews, our data on this conflict are secondhand, from the press and from interviews with other individuals directly involved in the events and conflicts of the time.
} 
Philips have been published in the Ghanaian press ${ }^{11}$ with Busumtwi's statements to point out various forms of dissimulation and omission. ${ }^{12}$ The second accusation and other major ethical issue raised by this controversy was the lack of consent from women enrolled in the trial. Following the statements of Busumtwi, the Navrongo Research Center admitted that they had not sought the individual consent of the women enrolled in the trial, casting doubt on the seriousness of the trial. Thus, in July 2010, the regional director of the Upper-East region (GHS) announced the departure of Columbia researchers and the consequent suspension of Motech RCT, ${ }^{13}$ which marked the end of the collaboration with Columbia University. The first victim of this conflict was the GHS, as it was ousted from its central role in the project by virtue of its long-standing collaboration with Columbia. The Ghanaian Ministry was unable to provide any evidence of Motech ownership at that time. Today, it neither owns the Motech platform nor has access to the data it hosts; Grameen and BMGF are the only ones to be able to use Motech and all the health data collected by the device. Some interviewees say that the controversy surrounding the RCT was used as a pretext to entrust the total management of Motech to the Grameen Foundation.

\section{No public results, no evidence?}

From July 2010 to September 2014, the Motech project continued to exist, deployed in several parts of Ghana, no longer as a clinical trial but as a quasi-experimental study of mHealth. This intermediate status indicates the conversion of the trial to another form of intervention and the search for another principle of scientific legitimacy. The latter is no longer presented as a real experimental study, but as an action-research study that takes up certain principles of scientific practice without respecting all its constraints. For the stakeholders of the project, Motech had many challenges, not only to answer a research question but also to test constraints and technical solutions, project logistics, costs and resources, to evaluate a market and potential products, all in an open-air laboratory. Once Columbia had been squeezed out, the research stakes of the Motech project became peripheral and the knowledge emerging from this experience was reformulated in terms of "lessons learned" published by the Grameen Foundation in 2011 and 2012 (Grameen Foundation 2011; Grameen Foundation 2012). This post-facto production, this form of selfvalidated knowledge associated with the terms "lessons learned" or "best practices" means that the programs were first put in place urgently without pre-evaluation and then selfproduced proofs were postulated by the actors in charge of deploying the devices to justify the prolongation of these interventions. This follows exactly the pattern already identified by Nguyen on HIV programs. As Nguyen explains a "government-by-experimentation" is caracterized by a form of ongoing experimentation, an endless search for evidence to maintain the devices, often based on post-facto or self production of knowledge by the program itself (Nguyen 2009).

\footnotetext{
11 "Yaa Bosumtwi Fights and Stands Firm against Columbia University’s Threats | Diasporian News 2010-05-09" 2015)

${ }^{12}$ Yaa Busumtwi, Video Press release, 15th May 2010.

13 "Technically, all projects of the University including Motech have grounded to a halt: Dr John Koku Awoonor-Williams, Regional Director of Health Services” in “One Woman's Agitations Halts Work on Research Project." | General News 2010-07-29' 2015.
} 
Indeed, the conversion of the scientific project into a technology development action has not led to the disappearance of any will for knowledge production. However, the form of this will has evolved considerably. Studying the impact of the mobile device remains a priority for BMGF and the failure of the collaboration with Columbia should not prevent the collection of evidence of the effectiveness of mHealth. BMGF has therefore provided additional funds to conduct another study on Motech in the central region of Ghana: "The Gates Foundation gave additional funding to do a new evaluation study of Motech. This time it's not a RCT it's a quasi-experimental design, $G$. is the intervention district and A. is the control district. They share the same kind of demographic and sanitary status. The school of public health is working with HitLab to do this evaluation, looking at health outcomes."14 This evaluation process was supported by a $\$ 2.75$ million special grant from BMGF.

This new study somewhat resembles a RCT, with an intervention site where Motech was implemented and a "blank" control site to compare. However, the design of the trial did not meet the criteria for random selection of participants and women were strongly encouraged to participate in the trial. Furthermore, the two sites were "leaky", meaning that participants from the blank site were going to the intervention site and vice versa. Apart from these important methodological considerations, the study was entrusted to an American consulting firm, the HitLab, specialized in ICT and health, and not directly to academics. However, the University of Ghana's School of Public Health was in charge of collecting the data, as a subcontractor of HitLab that would handle data analysis. The University of Ghana collected quantitative data using a questionnaire administered at the beginning of the project, prior to the implementation of Motech and 14 months after launch. A qualitative study was also conducted through ten focus groups discussions conducted 14 months after launch, five from women who used Motech and five from non-users. ${ }^{15}$ The University of Ghana transmitted all the data collected in August 2014 to HitLab, which was due to finalize the Motech study at the end of 2014. Three years later, this study was never published and access to the data of this study has never been effective, despite a July 2014 oral agreement with the principal investigator at HitLab. The University of Ghana has no rights to the data collected, and the Ghanaian research team could not communicate or publish about them.

Why have the funders invested so much money (almost $\$ 3$ million) and time (almost four years) in experimental studies whose results were neither presented nor made public to date? Two hypotheses come to mind. The first is that the results of the study do not show any positive effects of the program on the health of the beneficiaries. This hypothesis is partly verified by our qualitative survey and confirmed by several researchers (involved in the RCT and the quasi-experimental study). Indeed, they told us that the first results showed no significant impact of Motech on the three studied maternal outcomes-i.e., attendance at antenatal visits, institutional delivery, and infant birth weight. The other hypothesis, which in no way excludes the first, is that the "experimental" or "quasi-experimental" dimension of the

\footnotetext{
${ }^{14}$ Interview with B., Former GHS, Accra, 06/14.

${ }^{15}$ Officially hosted by the Department of Sociology of the University of Ghana in 2014, I was able to attend and take part in all the qualitative parts of the final evaluation of Motech in the central region with the research team from the University of Ghana School of public health.
} 
project aims less to describe the robustness of the knowledge that results from it than to define evidence of the marketability of this mobile product.

\section{3. "Market" as an ultimate goal}

Rottenburg explains that the emergence of this new regime of knowledge production and the commercialization of research are fondational aspects of neoliberal governance (Rottenburg 2009b, 436). As most of its devices are meant to be sold and evidence is needed to prove their value, the instrumentalization of knowledge production toward marketing goals is a fundamental component of mHealth. According to mHealth promoters (mHealth Alliance 2010; GSMA 2013), there are two possible commercial outcomes for mHealth projects when initial funding ends: to be funded and absorbed by the national health system or find a viable business model to switch to the mobile services market. During summer 2014, while Motech funding in Ghana was reaching an end, all stakeholders talked about transition and "exit strategies" for the program. Almost all the mHealth projects we studied in Ghana only had funding for two to three years maximum. Motech, the most durable of them, succeeded in chaining multiple grants. But at the end of this support in late 2014, how would the device be maintained and what kind of sustainability did its promoters then envisage?

\section{Exit strategies}

The Motech Ghana team has pursued two tracks of sustainability: "We are working towards a transition plan for Motech, there are issues of sustainability, costs really, so we are investigating if we can do both pieces of Motech, clearly the client data application is of interest for GHS but Mobile Midwife is too expensive because of airtime costs. So we are working with the Telcos to find sustainable solutions." 16 Thus, two solutions were mentioned to ensure the continuity of the device in Ghana, its recovery by the State, or its marketing by the biggest mobile phone operators (Telcos). This potential recovery by the Ghanaian State would never take place, and we confirmed that the Ministry of Health never had a hand on the device. But, the commercialization of the device actually materialized through the launching of "Mobile Midwife MTN."

In late 2014 - with the end of BMGF funding - the only initiative remaining of Motech Ghana was a commercial version of it, sold by Ghana's first mobile operator, MTN. In November 2013, MTN launched with the Grameen Foundation a paid version of the Motech application "Mobile Midwife MTN": "we launched a program with MTN, an SMS fee-based version of Mobile Midwife [...]. It's for MTN users only. The fee is split in two, 50\% for Grameen and 50\% for MTN." Mobile Midwife MTN was commercialized by the marketing department of MTN as a "value-added service," along with MobileTV or Mobile Banking. Approximately 5,000 women would have used the service in eight months, the cost of registration was 0,07 cedi and then 0,15 cedi per message $(\$ 0.03)$ at the rate of three messages per week, about $\$ 20$ would be necessary for a year of messages. During our fieldwork in summer 2014, Mobile Midwife MTN was still in its launch phase. The service

\footnotetext{
${ }^{16}$ Interview with A., Grameen F., Accra, 06/14.

${ }^{17}$ Interview with E., Grameen F., Accra, 06/14).
} 
was only accessible to MTN subscribers and will only be maintained if cost effective. The registration of women to Mobile Midwife must generate an added value for the operator, who pays half of the service's revenue to the Grameen Foundation. According to the marketing team of MTN, which met in July 2014, the service had not demonstrated its financial profitability at that time. According to the Grameen Foundation, it would be necessary to sell the service at a higher price per message to generate more income, a negotiation that the Grameen Foundation couldn't carry out with MTN in Ghana. Nevertheless, in September 2014, the Grameen Foundation launched a new partnership with the Indian Mobile Operator Airtel to commercialize Mobile Midwife in Nigeria. At 30 neras per message $(\$ 0.15)$, the service costs five times more than in Ghana for a potential market seven times larger. The paid version of Mobile Midwife was therefore promised to a bright commercial future in West Africa, and the business partners envisaged by Grameen Foundation were not limited to mobile phone operators.

\section{Towards micro health insurance and mass consumption markets}

When Mobile Midwife was exported to India in 2013, it was from the beginning deployed as a fee-based service that pregnant women had to pay for every time they would receive messages. The implementation of a fee-based version of Mobile Midwife was however only one of the many possible futures of the device. The Grameen foundation was working on other business strategies as explained by its employees: "We are trying to see if it's possible to bundle Mobile Midwife along with some commodities and some products, that the private sector can sell." 18 Among these products, the Mobile Midwife application could be part of a private health micro-insurance package. Subscribers to this health insurance may receive Mobile Midwife messages as part of their premium scheme. This service could also be sold with health or mass consumer products associated with pregnancy. For instance, women who have purchased a sponsored product (such as antiseptic or diapers) would access Motech messages for free. Finally, advertising and discount coupons from brands could sponsor the service. For example, a nutrition-related message from Mobile Midwife could be associated with a particular food product and benefit from a coupon received by SMS to get a discount price on that same product. These "combined offers" would make it possible to finance the costs of the device while making it paid by the beneficiaries at a lower cost, according to the promoters of Motech. In any case, the beneficiaries directly and/or indirectly pay the service. While the Motech business model is still not stabilized, the Mobile Midwife application is perceived by several stakeholders as a commercial product that would compensate for costs and even generate profits like other value added services of the mobile economy.

From philanthropic grants to the commercialization of the device, Motech's itinerary echoes the notion of "philanthro-capitalism" - a way to deploy new markets through a good cause (Bishop and Green 2008). This term has since been taken up by several authors to explain a new way of defining many global health and development programs financed by private actors (Global Health Watch 2011; Aneja 2016; Martens et al.; Seitz 2015). The itinerary of

\footnotetext{
${ }^{18}$ Interview with E., Grameen F., Accra, 06/14.
} 
Motech in Ghana and India illustrates the commercial turn that mHealth can take. Initially conceived as a randomized controlled trial (RCT), Motech Ghana did not start with obvious mercantile characteristics. Indeed, it was positioning itself as a free service offered to pregnant women and healthcare workers. Nevertheless, the world of mobile phones and mobile applications reinforces this mercantile approach and dramatically draws mHealth towards commercial consumption practices. The commercial dimension of Motech will be strengthened over time and the launch of the paid application by MTN in Ghana in 2013 marks a decisive turn towards markets for Motech; Motech then becomes a product of the mobile economy provided by a multinational company. Launched at the same time, the Indian version of Motech was conceived from the beginning as a marketing operation. This article demonstrates how mHealth can be used as a strategy to develop new markets in the Global South and the intermingling of scientific and market based evidences in this venture.

\section{Conclusion}

Motech in its "experimental" form illustrates the inversion of scientific knowledge and action (Nguyen, 2009), the importance of a "technical core" (Rottenburg 2009b) and a mercantile vision of biomedical research (Petryna 2009) that characterizes the increasingly neoliberal governance of knowledge production. The technical device is at the heart of Motech; in itself it constitutes a justification of the program. This form of experimentation is at the origin of a reversal in the production of empirical knowledge, so practice produces the knowledge that justifies it in return. By experimenting with this mobile health device in Africa and then deploying it in India, based on the "lessons learned" from the African project, ${ }^{19}$ Motech selfjustified its presence and its usefulness throughout the world. On the basis of the African experimentation, the device was established in India, without any in-depth analysis of its impact. As the rest of its story tells, Motech would no longer clutter up its expansion with scientific considerations.

From the construction of a research protocol to the sale of a commercial product, the itinerary of Motech illustrates an interesting shift found in technological innovation processes. But the case of Motech raises specific questions. The first phase of experimental research on the device has never been conclusive and no results have so far been presented on the impact of Motech on health outcomes. ${ }^{20}$ The clinical trial was not completed and the scientific partnership - broken at the beginning of the project - did not allow the production of scientific data on the effects of this device. Yet the program continued to exist and deployed on new grounds to reach more beneficiaries. After several years of existence, more than 10 million dollars invested and 30,000 targeted women, the only sustainable solution for Motech in Ghana was direct marketing from mobile operators to pregnant women, a total absorption of the technology by the mobile economy. In the literature presented above, clinical trials, and randomized controlled trials generate knowledge and allow forms of evaluation, even if

\footnotetext{
19 Grameen Foundation. "MOTECH early Lessons Learned," March 2011. Grameen Foundation. "MOTECH Lessons Learned," September 2012

${ }^{20}$ To date the sole scientific article published on Motech after its implementation focused on the level of reception of Motech messages among women. It shows that "Only $25 \%$ of pregnant women received and listened to at least 1 first trimester message. By 6-12 months postpartum, less than $6 \%$ of enrolled women were exposed to at least one message" (LeFevre et al. 2017, 1).
} 
these forms can be part of the self-legitimization of practices. In the case of Motech, no impact analysis supports the interventions, which however persist and are extended. But Motech holds in common with other experimental policies the characteristics of an intervention that is simultaneously authorized by an emergency, a technical rationality, and scientific legitimacy. In this context, Motech nevertheless remains an experimental intervention, while pushing to the extreme the motive of a rationality without content.

\section{AUTHOR BIO :}

Marine Al Dahdah is a sociologist and a postdoctoral fellow at IFRIS-Cermes3 (Paris) and a $\mathrm{CSH}-$ Delhi research associate. She holds a $\mathrm{PhD}$ in Sociology from Paris Descartes University. She has been working on the use of mobile phones and digital tools to improve health in Asia and Africa.

\section{ACKNOWLEDGMENTS}

I am grateful for the insightful comments made by the anonymous reviewers and the careful suggestions and direction provided by the editors.

\section{DECLARATION OF CONFLICTING INTERESTS}

The author declared no potential conflicts of interest with respect to the research, authorship, and/or publication of this article.

\section{REFERENCES}

Awoonor-Williams, John K., Ayaga A. Bawah, Frank K. Nyonator, Rofina Asuru, Abraham Oduro,

Awoonor-Williams, John K., Elias Kavinah Sory, Frank K. Nyonator, James F. Phillips, Chen Wang, and Margaret L. Schmitt. 2013. "Lessons Learned from Scaling up a Community-Based Health Program in the Upper East Region of Northern Ghana." Global Health: Science and Practice 1 (1): 117-133.

Banerjee, Abhijit V, Esther Duflo, and Julie Maistre. 2012. Repenser la pauvreté. Paris: Éd. du Seuil.

Bédécarrats, Florent, Isabelle Guérin, and François Roubaud. 2013. "L'étalon-or des évaluations randomisées : du discours de la méthode à l'économie politique.” Sociologies pratiques 27 (2): 107.

—. 2017. "All That Glitters Is Not Gold. The Political Economy of Randomized Evaluations in Development: The Political Economy of Randomized Evaluations in Development." Development and Change, December. https://doi.org/10.1111/dech.12378.

Bishop, Matthew, and Michael Green. 2008. Philanthrocapitalism: How the Rich Can Save the World. New York: Bloomsbury.

Faulkner, William N. 2014. "A Critical Analysis of a Randomized Controlled Trial Evaluation in Mexico: Norm, Mistake or Exemplar?” Evaluation 20 (2): 230-43. https://doi.org/10.1177/1356389014528602.

Fejerskov, Adam Moe. 2017. "The New Technopolitics of Development and the Global South as a Laboratory of Technological Experimentation." Science, Technology, \& Human Values 42 (5): 947-68. https://doi.org/10.1177/0162243917709934.

Foucault, Michel. 1994. “La Gouvernementalité, Texte No 239.” In Dits et Écrits. Vol. 3. http://michel-foucaultarchives.org/spip.php?page=biblio\&support=Cours\#resultats.

Grameen Foundation. 2011. "MOTECH Early Lessons Learned."

GSMA. 2013. "ANALYSIS Scaling Mobile for Development Harness the Opportunity in the Developing World."

$\begin{array}{llllll}\text { 2014. "GSMA } & \text { MHealth Tracker." } & \text { Accessed } & 16 & \text { January } & 2014 .\end{array}$ http://www.mobileworldlive.com/mhealth-tracker. 
Jatteau, Arthur. 2014. "Expérimenter le développement ?" Genèses, no. 93 (February): 8-28.

LeFevre, Amnesty E., Diwakar Mohan, David Hutchful, Larissa Jennings, Garrett Mehl, Alain Labrique, Karen Romano, and Anitha Moorthy. 2017. "Mobile Technology for Community Health in Ghana: What Happens When Technical Functionality Threatens the Effectiveness of Digital Health Programs?" BMC Medical Informatics and Decision Making 17 (1). https://doi.org/10.1186/s12911-017-0421-9.

MacLeod, Bruce, James Phillips, Allison E. Stone, Aliya Walji, and John Koku Awoonor-Williams. 2012. "The Architecture of a Software System for Supporting Community-Based Primary Health Care with Mobile Technology: The Mobile Technology for Community Health (MoTeCH) Initiative in Ghana." Online Journal of Public Health Informatics 4 (1). http://www.ncbi.nlm.nih.gov/pmc/articles/PMC3615808/.

Malone, Ruth E. 2003. "Distal Nursing." Social Science \& Medicine 56 (11): 2317-2326.

Marks, Harry M. 2000. The Progress of Experiment: Science and Therapeutic Reform in the United States, 1900-1990. Cambridge University Press.

mHealth Alliance. 2010. "Barriers and Gaps Affecting MHealth in Low and Middle Income Countries."

Nguyen, Vinh Kim. 2009. "Government-by-Exception: Enrolment and Experimentality in Mass HIV Treatment Programmes in Africa." Social Theory \&\#38; Health 7 (3): 196-217. https://doi.org/10.1057/sth.2009.12.

Ntsua, Stephen, Placide Tapsoba, Gloria Quansah-Asare, and Frank K. Nyonator. 2012. "Repositioning Community-Based Family Planning in Ghana: A Case Study of Community-Based Health Planning and Services (CHPS)." Washington, D.C: The Population Council. http://www.popcouncil.org/uploads/pdfs/2012PGY_CaseStudyCHPS.pdf.

Ofosu, Anthony and James F. Phillips. 2013. "The Ghana Essential Health Interventions Program: A Plausibility Trial of the Impact of Health Systems Strengthening on Maternal \& Child Survival." BMC Health Services Research 13 (Suppl 2): S3.

"One Woman's Agitations Halts Work on Research Project | General News 2010-07-29." n.d. Accessed 17 February 2015. http://www.ghanaweb.com/GhanaHomePage/NewsArchive/artikel.php?ID=187112.

Patrick, Kevin, William G. Griswold, Fred Raab, and Stephen S. Intille. 2008. "Health and the Mobile Phone." American Journal of Preventive Medicine 35 (2): 177-81. https://doi.org/10.1016/j.amepre.2008.05.001.

Petryna, Adriana. 2009. When Experiments Travel: Clinical Trials and the Global Search for Human Subjects. Princeton: Princeton University Press.

Rottenburg, Richard. 2009a. Far-Fetched Facts: A Parable of Development Aid. Inside Technology. Cambridge, Mass: The MIT Press.

2009b. "Social and Public Experiments and New Figurations of Science and Politics in Postcolonial Africa." Postcolonial Studies 12 (4): 423-40. https://doi.org/10.1080/13688790903350666.

World Bank. 2011. "Mobile Applications for the Health Sector." Washington: World Bank. http://siteresources.worldbank.org/INFORMATIONANDCOMMUNICATIONANDTECHNOLOGIES/Reso urces/mHealth_report_(Apr_2012).pdf.

"Yaa Bosumtwi Fights and Stands Firm against Columbia University's Threats" | Diasporian News 2010-05-09. $\begin{array}{llll}\text { n.d. } & \text { Accessed } & 23 & \text { January }\end{array}$ http://www.ghanaweb.com/GhanaHomePage/diaspora/artikel.php?ID=181742. 